\title{
Comentarios
}

\section{Democracia como forma de vida}

Recientemente ha sido publicado por parte del gobierno - y redactada por un grupo de intelectuales y profesionales que integran la Comisión de Desarrollo- la propuesta de nación denominada: $B \boldsymbol{B}$ ses para el plan de nación (en adelante nos referiremos a ésta como BPN). En ella se recoge un cúmulo de sugerencias del "cómo debe ser" el país ante los desafíos que presentará el tercer milenio y tras la herencia del Acuerdo de Chapultepec tenida como horizonte de acción. El deber ser que nos muestra dicho documento nos ubica no en un plano de efectividades, realizaciones inmediatas o de acciones consumadas. Más bien, es una propuesta, un programa encaminado hacia la edificación de un país distinto al que hemos conocido durante estos últimos años o al que la memoria histórica nos ha develado desde los orígenes de aquél. Por tanto, ese deber ser nos introduce en el plano de la ética o, si se quiere, en el plano de la reflexión sobre la conducta ciudadana, de las fuerzas sociales, los partidos políticos y el gobierno. Sin embargo, en esta ocasión no descamos discutir los alcances éticos de la propuesta y las responsabilidades colectivas e individuales dentro de un enfoque normativo que pueden desprenderse de ella. Más bien, queremos comentar uno de los puntos que en dicho documento aparece esbozadamente y que creemos que sin ninguna discusión abierta sobre el mismo se puede caer en muchos desvaríos. Este punto lo hemos denominado "la democracia como forma de vida". Y aunque el documento no utiliza dicho término, nuestra utilización procede de la impresión que la lectura de las BPN nos ha causado.

Vamos a partir de una afirmación que encontramos en las BPN. Dice así: "Hay que desplegar en el país una sociedad (...) donde la participación política del ciudadano sea cotidiana y la democracia impregne realmente todo el hacer social"'. Dicha afirmación nos servirá para apuntar hacia dónde va nuestro problema a tratar: la democracia como régimen vital. De hecho, el documento ofrece una definición — si así se le puede llamar- de democracia: "La Democracia como método de vida para asegurar el equilibrio político, la estabilidad social y el progreso ordenado y sostenido"2. Vistas las cosas de esa manera, consideramos sumamente positivo la puesta en común de un concepto no restrictivo de democracia. Y es que tradicionalmente hemos estado acostumbrados a escuchar y hasta hemos visto defender con estoicismo por parte de gobiernos pretéritos y contemporáneos o por otras esferas de la sociedad un concepto de democracia única y meramente como régimen político. La democracia se entendió -y lamentablemente se sigue entendiendo- como la participación ciudadana en la elección de sus representantes. Democracia se convirtió en sinónimo de "votos", "urnas electorales", "comicios electorales", e.tc.

La extensión de la democracia más allá del ámbito procedimental en materia electoral o más allá de la representación popular a través del Primer Or-

1. Bases para el plan de nación, p. 12.

2. Ibid., p. 9. 
gano del Estado debe llevarnos a reflexionar sobre el por qué ésta, entendida como forma de vida o "método de vida", no ha tenido una consistencia propia en nuestro país durante su historia $y$, además, debe llevarnos a reflexionar sobre cómo deberíamos legitimar su permanencia en nuestro mundo individual y coleclivo.

Han sido la dependencia, el paternalismo y el autoritarismo (como una variante del paternalismo) los componentes históricos que han modelado estructuralmente tanto la sociedad latinoamericana como la salvadoreña. En ese sentido, nuestra región latinoamericana - y hablamos de América Latina y no sólo de El Salvador porque ha habido una historia común que no se puede obviar- desde la conquista y colonización europea, se vio forzada a depender económica y políticamente de las metrópolis. Esta dependencia configuró los modos y las relaciones de producción. Las riquezas de América se extraían para satisfacer la economía europea. La producción local se orientó a una economía de subsistencia y de manutención del aparato burocráticoadministrativo del régimen colonial. Por otro lado, la relación política entre América y la Península fue traducida al verticalismo entre corona-súbditos. Los habitantes de América fueron concebidos como "hijos pequeños" a los cuales había que cuidar como también formar. Esta preocupación por una educación dentro de la tradición cristiana y bajo el esquema de la cultura Occidental no significó una ausencia de métodos coercitivos para con los indígenas, mestizos u otros grupos sociales. De esa manera fue gestándose una estructura de dependencia, paternalista y autoritaria en América Latina. Posterior a la colonia, los distintos estados desplegaron esta herencia peninsular. Dentro de dicha estructura se fraguó un modelo de ser humano caracterizado por la exclusión, la falta de autonomía, juntamente con la creencia en la necesidad del castigo para hacerlos acluar.

La contradicción entre el establecimiento de la democracia en cuanto procedimiento político por los estados liberales de los siglos XIX-XX y la ausencia de aquélla en el mundo cotidiano ha sido y continúa siendo evidente. La familia, la enseñanza, los centros laborales, los partidos políticos, las organizaciones de diversa índole están configuradas y reproducen a la vez las variables históricas a las que hemos apuntado arriba. No es extraño, entonces, que el documento Bases para el plan de nación proponga como punto medular para la construcción de un nuevo país la participación ciudadana en las distintas esferas nacionales. Inclusive, el problema de la identidad cultural está cifrado en claves de participación ciudadana en torno a un proyecto común. Según el documento, con la participación de la ciudadanía sería posible enfrentar los modelos marginantes bajo los cuales está configurado El Salvador, dado que éstos han caracterizado tradicionalmente la realidad profunda de la problemática salvadoreña.

Pero habrá que interpretar y ubicar esta preocupación de las BPN dentro de un proceso más global en el que la comunidad de naciones se están percatando de dicha ambiguiedad en el interior de sus respectivas comunidades. Así, Norberto Bobbio lo ha señalado como un "proceso de democratización" en el que la democracia política da paso a la democracia social. Se trata de un cambio que están experimentando muchas naciones y por ello Bobbio lo ha formulado de la manera siguiente: "de la democratización del Estado a la democratización de la sociedad"'. En ese sentido, a partir de ahora sólo será posible hablar de un verdadero avance democrático si la democracia verdaderamente ha ganado los diversos espacios sociales que antes lo ocupaban las figuras autoritarias familiares, escolares, labores, etc.

Sin embargo, si uno de los propósitos confesos de las BPN es señalar que en una sociedad como la nuestra se "debe" realizar el tránsito que bien nos ha formulado Bobbio, dicho documento queda corto precisamente en el punto de la participación ciudadana. Hemos afirmado que para las BPN la problemática salvadoreña se ha caracterizado por la "marginación" de carácter estructural. Pero resulta que su concepción de estructuralidad adolece de un grave problema cuando afirma que la realidad más profunda de la situación salvadoreña ha sido la "marginación sociocultural". Ello no supondría -0 al menos no queda del todo explícito- que una de las notas dominantes en la concepción estructural de la realidad salvadoreña haya sido la exclusión de los amplios sectores de la población en las decisiones, participaciones y acciones dentro del ámbito económico. La idea de estructuralidad decantaría así en una idea de estructura a medias, si es que es posible dicho término.

3. Bobbio, N., El futuro de la democracia, México: Fondo de Cultura Económica, 1992, pp.42-43. 
Si realizamos una observación rápida de nuestra historia nos daremos cuenta que el modelo antropológico salvadoreño y latinoamericano caractcrizado por la exlusión, falta de autonomía y receptor de castigo no hace alusión exclusivamente al ámbito sociocultural. Es muy cierto que la figura de ser humano que se ha sostenido y asumido en América Latina ha sido la de un ser humano que no ha encontrado todavía su ctapa de madurez. Por ello, ha sido "conveniente" guiarlo paternalmente en la enseñanza; conveniente cancelar la autonomía a las mujeres en el hogar; necesario y útil imponer orden y autoridad a través del castigo físico. Pero también se ve como normal la exclusión de muchos a su derecho al trabajo; y aquéllos que lo tienen, de no gozar del respeto a su dignidad en el interior de los centros de producción. Como se ve, el autoritarismo y el paternalismo como formas de vida heredados de la colonia y desplegados durante la historia de nuestro país se presentan en los distintos ámbitos del mundo vital colidiano. Por ello tiene razón Bobbio al interrogarse si es suficiente que tan sólo una esfera de la sociedad - la política- pueda experimentar una democratización mientras las otras formas sociales no. Y aunque es discutible que la esfera política goce de una verdadera democratización en América Latina, no nos parece aceptable ni decorosa defender la anterior contradicción.

Legitimar la presencia y permanencia de una democratización de la vida se convierte hoy en necesaria. Pero dicha necesidad preocupante no convierte la presente problemática en una tarea de fácil solución. Lo que sí es cierto es que si queremos legitimar una democracia como forma de vida se vuelve esencial rastrear la apoyatura teórica bajo la cual ha descansado el paradigma dependiente, paternalista y autoritario de nuestra vida. El origen hislórico de esta apoyatura teórica lo hemos visto someramente arriba. Se trata de los inicios que tuvo nucstra América con una relación vertical, autoritaria, dependentista con la metrópoli. En ese contex10, el espíritu occidental de la época quizás pueda resumirse bajo la frase de "egoencia del cogito". Esta "egoencia del cogito" significó no sólo el descubrimiento del "Yo", del cogito, en cuanto sujeto dubitativo de las tradiciones (el caso típico, claro cstá, es el subjetivismo existencial y metodológico cartesiano), sino también, significó la proyección de

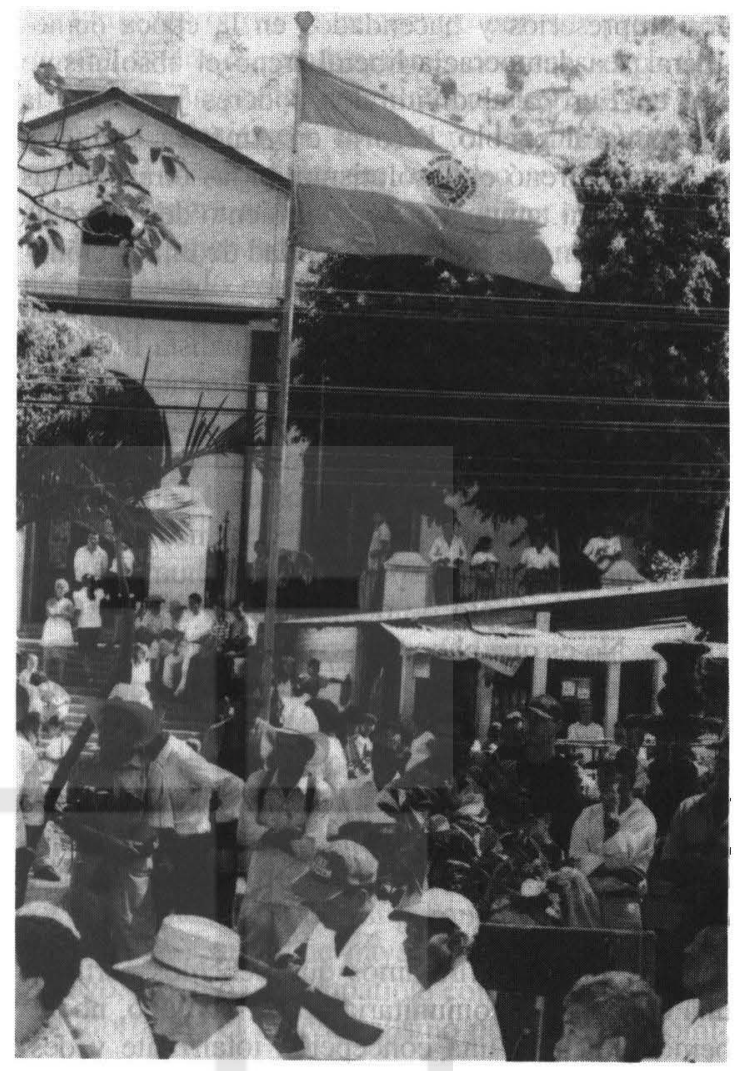

ese "Yo" como sujeto conquistador y esclavizador. Es así como América no se descubre. Quizá se inventa, pero no hay duda que se le somete. Sus habitantes se convierten no en otros sujetos, sino en objetos militares o en objetos de guía paternal. El autoritarismo y paternalismo del "Yo" occidental puede verse en españoles de aquella época tan dispares en sus propósitos, como Ginés de Sepúlveda y Bartolomé de las Casas, respectivamente.

Posteriormente, las democracias liberales implantadas en América Latina durante su vida republicana no solucionaron la "egoencia del cogito" heredado de la colonia. Más bien, le suministraron nuevos cauces teóricos. Estas democracias liberales se fundaban en una concepción individualista de sociedad en la que "el pueblo" estaba conformado por todos aquellos que aportaban riqucza a la nación. El "yo conquisto" de la metrópoli colonialista da paso, entonces, a la comunidad de "yocs" conformada

4. Marquínez Argote, G., "Una lectura latinoamericana de Descartes” en Realitas III-IV, Vol. IV (1979), pp. 367. 388. 
por empresarios y hacendados en la época demoliberal. La democracia liberal frenó el absolutismo real en Europa al dividir los poderes y otorgar la soberanía al pueblo. Pero ni en América Latina ni en Europa frenó el absolutismo en las otras esferas de la vida ni tampoco su otorgamiento de soberanía residió realmente en la colectividad de una nación.

$\mathrm{Si}$ la idea moderna de democracia ha estado apoyada en una concepción individualista liberal y, a la vez, se ha defendido tradicionalmente en nuestros países una visión antropológica desde la colonia en donde los sujetos humanos han sido degradados a simples objetos o a sujetos excluidos, dependientes o inmaduros, entonces debemos partir de una concepción comunitaria de ser humano para orientar el concepto de democracia a otras esferas vitales. No es que el concepto de democracia vaya a generar qué idea de ser humano sea más adecuada para acoplarse a dicho estilo de vida. Más bien, al repensar una antropología comunitaria estaríamos evaluando cuáles son las condiciones favorables para que las personas puedan desarrollarse individual y socialmente en el interior de sus comunidades.

Pero cuando afirmamos que debemos partir de una concepción comunitaria de ser humano, no debemos entender una concepción totalizante y despersonalizante del mismo. Ese fue el problema al que se enfrentaron algunos pensadores después de la II Guerra Mundial por las experiencias vividas dentro de los sistemas totalitarios. María Zambrano fue una de esos pensadores. Esta filósofa española insistía que una democracia como régimen político debía ser la resultante de una sociedad democrática. Por lo que el camino recorrido en el mundo occidental había sido el inverso. Pero lo importante de su razonamiento para nuestro caso estriba en la idea de una sociedad democrática que exija o propicie a los hombres ser "personas". De ahí que este mundo democrático deberá ser un mundo en el que existan las particularidades sin ningún impedimento; donde haya una convivencia de múltiples que no sean degradados a masa ${ }^{5}$. Partiendo del análisis de Zambrano diremos que la dimensión comunitaria del ser humano no tiene porqué devenir en un proceso de deshumanización o convertirse en un proceso de masificación. La comunidad, lo colectivo, lo social no tiene porqué ahogar las iniciativas, los desarrollos y las potencialidades de cada persona.

De lo que se trata es de recobrar la dimensión perdida del hombre. Esta dimensión olvidada pucde figurarse no como una línea vertical que inicia desde el "yo" hasta los "otros", sino como un círculo en donde tanto el "yo" como los "otros" tienen igual participación. Ante el "yo" y sus pretensiones autoritarias, paternales y excluyentes se hace necesario transitar a un "nosotros" en donde sea superado el paradigma individualista moderno-ilustrado. La categoría del "nosotros" nos remite entonces a la dimensión extraviada y muchas veces cancelada del ser humano en América Latina y en nuestro país, y nos remite a la búsqueda de una ampliación de los espacios para la democracia. La preocupación teórica por ese tránsito ha comenzado a realizarse por parte de algunas filosofías contemporáneas. Debemos decir que a pesar de algunas crílicas que recaen en sus planteamientos, la ética del discurso, por ejemplo, ofrece algunas pistas con las que podemos acercarnos a este problema que estamos tratando. Apel ha sostenido que su ética del discurso, en cuanto ética de la responsabilidad, ha logrado el tránsito del yo al nosotros desde el ámbito dialógico". Se trata del paso del "yo argumento" al "nosotros argumentamos" en donde haya una cooperación solidaria entre todos los individuos para la fundamentación de normas morales y jurídicas a través del discurso argumentativo.

Sin embargo, para establecer las condiciones de diálogo y cooperación social se requiere previamente una idea de ser humano no sólo dialogante (animal racional, como dirá la tradición filosófica) ni tampoco - ni mucho menos - la de un ser altruista que coopera con los demás y para los demás por mero accidente. Es indispensable acercarnos a qué entenderemos por la dimensión del "nosotros" como punto básico de discusión. Referencias sobre una filosofía del "nosotros" o de la alteridad encontramos con mucha fuerza y vigor argumentativo sobre todo en el período poshegeliano o en nuestra época que dice romper con los artilugios de la Ilustración. Feuerbach, Levinás, Schütz, entre otros, han abordado la relación Yo-Tú desde ángulos diversos. También en América Latina la reflexión filosoffica ha reparado más de alguna vez en dicha

5. Zambrano, M., Persona y democracia, Madrid: Ediciones Siruela, 1996, pp. 169-208.

6. Apel, K-O., Teoría dé la verdad y ética del discurso, Barcelona: Paidós, 1995, pp. 148-149. 
calcgoría. Veamos lo que nos dice el argentino Juan Carlos Scannone, no para realizar una exposición pormenorizada o una defensa de su concepto, sino para tener a la mano una idea de tal categoría en vistas a intentar señalar por dónde es posible legitimar a la democracia como estilo de vida.

Para Scannone, el "nosotros" como categoría filosófica que interpreta o da sentido a una realidad sólo tiene sentido y consistencia junto a otro término: el "estamos". Este "nosotros estamos" se convierte así cn el nuevo punto de partida de la filosolía latinoamericana. A su juicio, "el nosotros no es la universalización del yo ni es el sujeto trascendental de la relación sujeto-objeto; sino que implica, además del yo, lambién el tú y el él (y supone el $E()^{\prime}$, que no son reduclibles al yo ni siquiera comprendidos trascendentalmente"7. Nos bastan esos elementos que nos proporciona Sacnnone para que digamos que la categoría del "nosolros", que nos sirve para legitimar un estilo de vida democrático, implica a los "demás" (en el hogar, a la mujer y sus hijos; en los centros de producción, a los trabajadores; en la enseñanza, a los estudiantes, etc.). Se preguntaría, entonces, cómo realizar la incorporación y la participación de los "otros" para diluir el esquema del "yo" individualista, paternal y excluyente en cada esfera de la sociedad. Ante ello, debemos decir que en este momento es donde se ve la necesidad de una tarea interdisciplinaria de nuestro problema. La legitimación desde la filosofía no basta. Es muy cierto. Se necesitaría para el caso, el auxilio de las ciencias humanas y sociales para discutir el cómo democratizar los espacios vitales de las personas y evitar cualquier riesgo que pudiese desprenderse de ello. Sin embargo, nuestro propósito ha sido el de reflexionar por dónde puede ir una fundamentación. Lo otro es una tarea pendiente todavía.

La irreductibilidad de los otros al "yo" planteada por Scannone supone una crítica a la "egoencia del cogito", a una filosofía de la conciencia que prima al sujeto cognoscente sobre lo conocido; pero sobre todo, una crítica al sujeto cognoscente como capaz de darle sentido a las cosas, de imponerle sus leyes o de darles significado a través del raciocinio. La irreductibilidad de los otros al yo nos conduce a un descentramiento del "yo" verticalista y excluyente. A la vez, nos conduce a un encuentro cara a cara con los otros: un encuentro con sus preocupaciones, intereses, motivaciones comunes o particulares. Estc encuentro es un reconocimiento del otro como un semejante o congénere. La dimensión comunitaria y social del ser humano se patentiza en este encuentro, aunque desde la niñez o mucho anles haya comenzado. Pensemos nada más cómo el niño va siendo configurado por su familia y cómo los "otros" le van guiando y moldeando su existencia.

Ahora bien, es importante no perder de vista que dentro de una concepción comunitaria de ser humano no se disuelve el "yo" por más que quede descentrado. La pérdida del puesto que le había otorgado la modernidad no implica su ahogamiento en las relaciones interpersonales. Si así fuese, la dimensión social del hombre sería una masificación a ultranza. ¿Queda ubicada la concepción comunitaria de ser humano en un plano de ecuanimidad entre el individualismo moderno -que para nuestro caso no se configura solamente en un paradigma insolidario sino, como hemos insistido, en paternalista y autoritario- y el colectivismo masificador? Debemos decir que sí porque un estilo de vida democrático, en donde haya participación, respeto, diálogo, etc., no es compatible con un estilo de vida que glorifique el individualismo posesivo económico-social ni tampoco con un estilo de vida en donde la despersonalización de los miembros de los diferentes grupos o fuerzas que constituyen la sociedad se considere lo más conveniente. El "nosotros" deberá, por tanto, no sólo recuperar la intersubjetividad concreta, sino también recuperar un equilibrio entre la dimensión personal y comunitaria. Adela Cortina lo ha planteado como una relación equilibrada entre la autonomía individual y la participación solidaria. Ella dice que "la democracia moralmente deseable y legítima no se reduce a un mero mecanismo, sino que consiste en un modelo de organización social, basado en el reconocimiento de la autonomía de los individuos (...) y en el reconocimiento de que la dirección de la vida comunitaria debe ser el resultado de la igual participación de todos. El respeto por la autonomla individual y colectiva sólo se adquiere desde una forma de vida participativa..."

El reconocimiento a la autonomia del individuo - como lo señala Cortina - alerta ante una posible

7. Scannone, J.C., "Un nuevo punto de partida en la filosofía latinoamericana" en Strómata (1980), No. 1-2, p. 31.

8. Cortina, A., Etica sin moral, Madrid: Tecnos, 1995, p.257. 
forma de masificación o colectivización que ha sido muy frecuente en los sistemas políticos democráticos latinoamericanos. Los sujetos, hombres y mujeres, denominados comunmente como el "pueblo", se han convertido en sujetos anónimos que adquieren importancia exclusivamente cuando entran en las reglas del juego democrático procedimental. $\mathrm{Ni}$ siquiera se les ha reconocido su pertenencia a tal grupo o fuerza social, ni mucho menos se han atendido sus necesidades. El reconocimiento de la autonomía de los individuos, de los otros como yo, de los congéneres, supone el respeto y la garantía a sus derechos materiales e intelectuales. Esta situación de igualdad de condiciones jurídicas no debe decantar en una simple valoración. Debe ser eco de una materialización en la vida cotidiana tanto en el inte- rior de la familia, los centros de enseñanza o las empresas. Es más, su efectividad en la realidad diaria supone el inicio de una actitud distinta de la que continúan apelando algunos liberalismos salvajes: el individualismo posesivo. Esta actitud de reconocimiento del "otro" (mujer, alumno, obrero...) como persona, como irreductible a mi "yo"; el percatarnos de sus problemas e intereses o el preocuparnos por ellos es lo que podemos denominar como una actitud solidaria. Es a partir de ese reconocimiento solidario como se posibilitaría el diálogo o la argumentación de la que nos habla Apel, para poder resolver los problemas en el interior de las esferas humanas.

\section{Sajid Alfredo Herrrera}

